\title{
RESEARCH
}

Open Access

\section{Trajectories of subjective cognitive decline, and the risk of mild cognitive impairment and dementia}

Tau Ming Liew ${ }^{1,2}$

\begin{abstract}
Background: In cognitively normal individuals, subjective cognitive decline (SCD) has been reported to predict $\mathrm{MCl}$ and dementia (MCl/dementia). However, prior studies mostly captured SCD at single time-points without considering the longitudinal course of SCD. This study examined whether the trajectories of SCD provide any added information — beyond one-time assessments of SCD—on the risk of $\mathrm{MCl} /$ dementia.

Methods: This cohort study included 5661 participants from the Alzheimer's Disease Centers across the USA, who were $\geq 50$ years and had normal cognition in the first-four annual visits (year 1 to year 4). The participants were evaluated for SCD in the first-four annual visits (year 1 to year 4), and followed-up almost annually (year 4 up to year 14) for incident $\mathrm{MCl} /$ dementia. SCD trajectories (as identified from latent-class-growth-curve-analysis) were included in Cox regression to estimate their risks of $\mathrm{MCl} /$ dementia, with analyses further stratified by age $(<75$ years versus $\geq 75$ years; based on median-split).

Results: Compared to those without SCD (in the first-four annual visits), Intermittent SCD (i.e., reported in 1-2 of the first-four annual visits) predicted a higher risk (HR 1.4) and Persistent SCD (i.e., reported in 3-4 of the first-four annual visits) predicted the highest risk (HR 2.2), with the results remaining significant even after adjusting for baseline SCD. Age-stratified analysis revealed that the risk associated with Intermittent SCD was only present in older individuals, while risk related to Persistent SCD was consistently present across the younger and older age groups. Age compounded the effects of the trajectories, whereby older individuals with Persistent SCD had $>75 \%$ probability of developing $\mathrm{MCl} /$ dementia by 10 years, in contrast to $<25 \%$ probability by 10 years in younger individuals with No SCD.

Conclusions: The findings demonstrate the utility of SCD trajectories-especially when used in combination with age strata-in identifying high-risk populations for preventive interventions and trials. They also suggest a potential modification in the current SCD criteria, with the inclusion of "persistent SCD over several years" as a feature of SCD plus.
\end{abstract}

Keywords: Subjective cognitive complaints, Trajectory, Utility, Mild cognitive impairment, Dementia, Cohort study, Cox regression

\footnotetext{
Correspondence: liew.tau.ming@singhealth.com.sg; ephltm@nus.edu.sg

'Department of Psychiatry, Singapore General Hospital, Outram Road,

Singapore 169608, Singapore

${ }^{2}$ Saw Swee Hock School of Public Health, National University of Singapore,

Singapore, Singapore
}

C C The Author(s). 2020 Open Access This article is licensed under a Creative Commons Attribution 4.0 International License, which permits use, sharing, adaptation, distribution and reproduction in any medium or format, as long as you give appropriate credit to the original author(s) and the source, provide a link to the Creative Commons licence, and indicate if changes were made. The images or other third party material in this article are included in the article's Creative Commons licence, unless indicated otherwise in a credit line to the material. If material is not included in the article's Creative Commons licence and your intended use is not permitted by statutory regulation or exceeds the permitted use, you will need to obtain permission directly from the copyright holder. To view a copy of this licence, visit http://creativecommons.org/licenses/by/4.0/ The Creative Commons Public Domain Dedication waiver (http://creativecommons.org/publicdomain/zero/1.0/) applies to the data made available in this article, unless otherwise stated in a credit line to the data. 


\section{Introduction}

Subjective cognitive decline (SCD) refers to the subjective perception of a decline in cognition (typically in the memory domain) among individuals with normal cognition (that is, in the absence of objective cognitive deficits) [1-3]. It is increasingly common with advancing age [4], with large community-based studies in the literature pointing to a prevalence of 50-60\% among older persons $[5,6]$. In recent years, SCD has gained attention as a key predictor for incident neurocognitive disorders. As shown in a recent meta-analysis [7], those with SCD had an annual conversion rate of $6.6 \%$ to mild cognitive impairment and $2.3 \%$ to dementia (in contrast to $1 \%$ in those without SCD); over a 4 -year period, $24.4 \%$ of those with SCD developed mild cognitive impairment and $10.9 \%$ developed dementia (in contrast to $4.6 \%$ in those without SCD) [7]. Most recently, SCD has been highlighted as a useful criterion in the diagnosis of prodromal neurocognitive disorders [1,8], with the 2018 NIA-AA research framework for Alzheimer's disease [9] incorporating SCD as a transition phase between normal cognition and early neurocognitive disorders.

Traditionally, most of the studies on SCD have measured SCD only at 1 time-point (that is, crosssectionally) $[7,8]$-this approach does not capture intraindividual variability in SCD or the longitudinal course of SCD. Such gap in the literature may potentially be critical because individuals can display different patterns of SCD over time [10] which may provide additional prognostic information beyond those captured by one-time assessments of SCD. Using a large sample and a longitudinal study-design, this study sought to:

(1) Identify the distinct patterns of SCD trajectories among cognitively normal individuals;

(2) Investigate the association between the SCD trajectories and the risk of mild cognitive impairment (MCI) and dementia; and

(3) Evaluate whether the SCD trajectories provide any added information regarding the risk of $\mathrm{MCI}$ and dementia, beyond those captured by one-time assessments at single time-points.

\section{Method \\ Study population}

This cohort study involves individuals recruited from the Alzheimer's Disease Centers (ADC) across the USA between 2005 and August 2019 (as available in the National Alzheimer's Coordinating Center database) [11]. Majority of the participants (90.0\%) visited the ADC to volunteer in research, while $9.9 \%$ visited the ADC to seek clinical evaluation and $0.1 \%$ had unknown reasons for participation. On an approximately annual basis, the participants took part in standardized assessments (which included clinical history, physical examination, and detailed neuropsychological testing) to evaluate for incident MCI and dementia. In the present dataset, some of the participants have received up to a maximum of 14 approximately annual assessments. For the purpose of this study, data from the first four annual visits (year 1 to year 4) were used to identify the trajectories of SCD, while data from year 4 onwards were used to investigate the association between the SCD trajectories and the incident of MCI and dementia. This analysis timeline is further depicted in Fig. 1. The study included participants who fulfilled the following criteria: (1) age $\geq 50$ years at year 1 ; (2) diagnosed as having normal cognition from year 1 to 4 (that is, participants had completed diagnostic evaluations and found not to have MCI or dementia in each of the annual visits); and (3) provided information on SCD in at least 3 out of the 4 time-points between year 1 and year 4. All contributing ADC obtained informed consent from their participants, as well as received approval by their local institutional review boards.

\section{Measures}

SCD was evaluated with a single yes/no question $(1=$ yes; $0=$ no) based on whether the participant reported "a recent decline in memory relative to previously attained

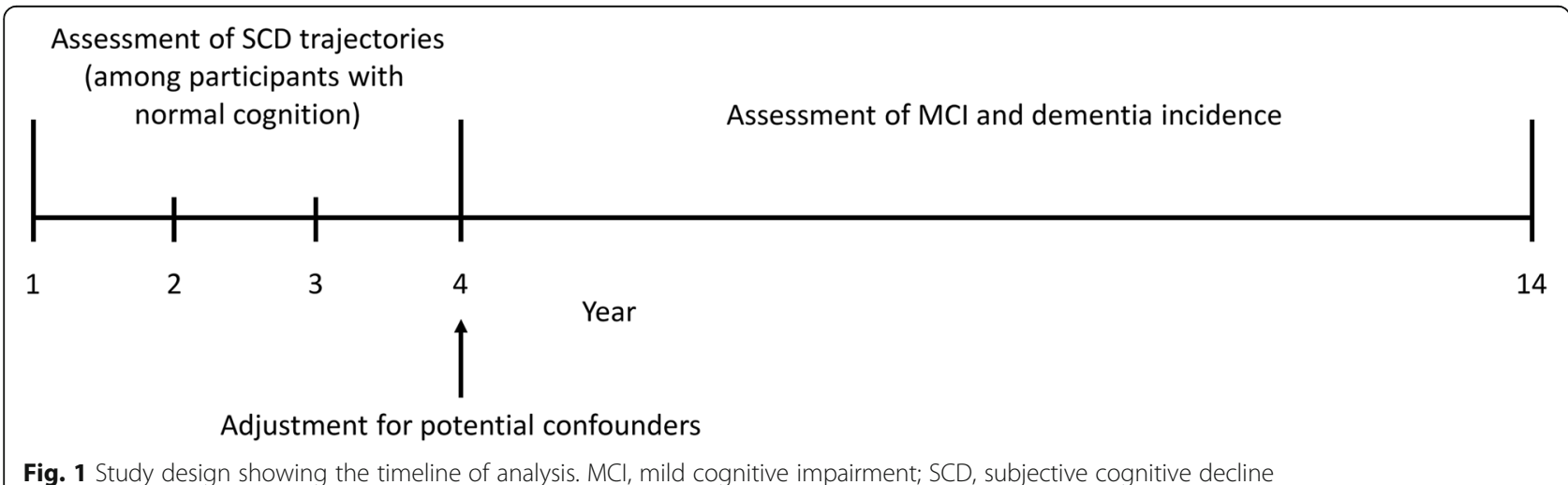


abilities." The focus on the memory domain is not inconsistent with the current evidence in the literature, particularly in the recently proposed SCD framework [1], where memory concerns have been suggested to demonstrate better likelihood (than other non-memory concerns) in detecting prodromal neurocognitive disorders [3].

The Mini-Mental State Examination (MMSE) [12], Geriatric Depression Scale (GDS) [13] and anxiety symptoms were also measured in this study and were included in the analyses as potential confounders. MMSE [12] is an 11-item measure of global cognitive function, focusing on the domains of orientation, memory, concentration, language, and constructional praxis. GDS [13] assesses the level of depressive symptoms over the past week using 15 yes/no questions-the responses are summed to produce a total score, with higher scores indicating higher levels of depressive symptoms. Anxiety symptoms were evaluated with a single yes/no question based on whether the participants have experienced "any signs of nervousness such as shortness of breath, sighing, being unable to relax, or feeling excessively tense" in the past month.

The diagnoses of MCI and dementia were made based on all available information from standardized assessments [11], with $69.7 \%$ made via consensus conference and the remainder made by single clinicians. MCI was diagnosed using the modified Petersen criteria [14]. Dementia was diagnosed using the McKhann (1984) criteria [15], DSM-IV (Diagnostic and Statistical Manual of Mental Disorders-Fourth Edition) criteria [16], or the McKhann (2011) criteria [10], with further classification into the primary etiologies of Alzheimer's dementia [10, 15], vascular dementia [17], frontotemporal lobar degeneration [18-24], dementia with Lewy bodies [24-26], and other etiologies.

\section{Statistical analyses}

Latent class growth curve analysis was first conducted to identify the trajectories of SCD during the first 4 years of the study (Fig. 1). Latent class growth curve analysis is a semiparametric analysis that classifies the participants into mutually exclusive groups with distinct trajectories of SCD [27], based on the presence or absence of SCD complaints from year 1 to 4 . For each participant, it computes the probability of belonging to the various trajectories and assigns the participant to a trajectory with the highest probability. Models with 1 to 6 trajectories were evaluated in the latent class growth curve analysis, with the binary responses of SCD $(1=$ yes; $0=$ no $)$ modeled using logistic models. To determine the appropriate number of trajectories, the Bayesian Information Criterion (BIC) and the Average Posterior Probabilities were used-BIC values which are lesser by at least 10 points indicate better model fit and parsimony; while Average
Posterior Probabilities should be at least 0.70 for all the assigned trajectories to indicate the adequacy of a model [28]. To determine the appropriate trajectory shape, for each model specifying a given number of trajectories, the linear and quadratic terms were included in the model and removed sequentially (starting from the higher-order, quadratic terms) if they were not significant $(p>0.05)$.

The identified trajectories of SCD were then included in the Cox proportional-hazard regression to evaluate their respective risks of MCI and dementia. Time-toevent was defined as the duration from year 4 onwards (Fig. 1) to the diagnosis of either MCI or dementia. The Cox regression adjusted for demographic information (age, sex, and ethnicity), known predictors of neurocognitive disorders (years of education, APOE e4 status, current smoking, diabetes mellitus, hypertension, hyperlipidemia, and MMSE score) [29], as well as potential confounders [30] that may predict both the exposureof-interest (SCD) and the outcome-of-interest (neurocognitive disorders), namely GDS score and presence of anxiety symptoms. GDS score was included as a potential confounder because depressive symptoms are strongly associated with SCD (exposure-of-interest) $[1,8,31,32]$, while at the same time, the presence of depressive symptoms has been shown to be an independent predictor of neurocognitive disorders (outcome-of-interest) [3, 33-35]. Similarly, anxiety symptoms are known to correlate with SCD (exposure-of-interest) [2], and the presence of anxiety symptoms has also been reported to predict neurocognitive disorders (outcome-of-interest) [33-39].

The proportional-hazard assumption of Cox regression was tested statistically based on whether the Schoenfeld residuals were associated with time-in the event there was significant violation of the proportional-hazard assumption ( $p \leq 0.05$ in the global test on statistical significance of non-proportionality), the variables that violated the proportional-hazard assumption were identified using the scaled Schoenfeld residuals and included in the Cox regression as stratified variables $[3,34,40]$. Inverse probability weighting (IPW) [41] was used in Cox regression to account for participants who did not have follow-up data beyond year 4. IPW is a well-accepted strategy to minimize potential bias in the results related to differential risks between those with and without follow-up data. The probabilities of being "complete cases" (those with follow-up data) were generated from logistic regression. The inverse of the probabilities was then used as weights in Cox regression, so that the results bear more semblance to those who dropped out and are less biased towards participants who provided follow-up data [3, 33, 34, 41]. Further details on IPW are available in Additional file 1. 
Three sensitivity analyses were conducted to evaluate the consistency of the results when some parts of the Cox regression were modified. They include:

(1) Additional adjustment for the presence of SCD at year 4, to investigate whether the SCD trajectories were more informative than one-time assessment of SCD at year 4;

(2) Using dementia as the primary endpoint (instead of the composite endpoint of $\mathrm{MCI}$ and dementia); and

(3) Redefining the identified trajectories using simplified rules that can be easily applied in routine practice.

Additionally, a stratified analysis was further conducted to evaluate the risks associated with SCD trajectories across different age groups, given that age is the most important risk factor of neurocognitive disorders $[42,43]$ yet the relationship between age and SCD has not been well understood. To facilitate the stratified analysis, participants were split into 2 equal-sized age groups based on the median age of the study sample (i.e., < 75 years and $\geq 75$ years). All statistical analyses were conducted in Stata (version 14), with the latent class growth curve analysis conducting using the "traj" package (built date: February 2016) in Stata [27].

\section{Results}

A total of 5661 participants were included in this study, with a median age of 75 (interquartile range, IQR 6981) and a median MMSE of 30 (IQR 29-30). Additional file 2 presents the flow diagram related to participant selection, while Additional file 3 shows the participant characteristics at year 4 , as well as the comparison between participants with and without follow-up data (beyond year 4). About one-fifth of the participants (18.9\%) only provided data for the trajectories of SCD (from year 1 to year 4) and did not contribute to the follow-up data (beyond year 4), while the rest of the participants had a median follow-up data of 4.0 years (IQR 2.1-6.8 years). During the follow-up period, 489 (8.6\%) converted to MCI, while 239 (4.2\%) converted to dementia (with 191 being Alzheimer's dementia, 8 vascular dementia, 16 mixed Alzheimer's/vascular dementia, 8 dementia with Lewy bodies, 2 frontotemporal lobar degeneration, and 14 due to other or unknown etiology).

In latent class growth curve analysis, 3 distinct trajectories of SCD were identified during the first 4 years of the study (Additional file 4). These 3 trajectories are further presented in Additional file 5. Trajectory 1 included $69.1 \%$ of the participants and likely represented those who did not report SCD in any of the 4 annual visits. Trajectory 2 included $18.1 \%$ of the participants and possibly represented those with Intermittent $S C D$ across the 4 years (i.e., those who reported SCD in approximately 1 to 2 time-points out of the 4 annual visits). Trajectory 3 included $12.8 \%$ of the participants and represented those with largely Persistent SCD throughout the 4 years (i.e., those who reported SCD in approximately 3 to 4 time-points out of the 4 annual visits). Table 1 compares the participant characteristics across these 3 identified trajectories. Compared to those with No SCD, participants with Intermittent or Persistent SCD had marginally higher age, lower MMSE scores, higher GDS scores, and higher proportion of anxiety symptoms. In addition, participants with Intermittent $S C D$ had a larger proportion of African American ethnicity, while participants with Persistent SCD had a larger proportion of APOE e4 allele as well as ethnicities other than White or African American.

The 3 trajectories of SCD were then included in Cox regression to evaluate their respective risks of $\mathrm{MCI}$ and dementia, with the results of unadjusted and adjusted hazard ratios (HR) presented in Table 2. Compared to those with No SCD, the risk of MCI and dementia increased incrementally from Intermittent SCD (HR 1.4) to Persistent SCD (HR 2.2). Participants with No SCD had a $25 \%$ probability of developing MCI or dementia by 8.0 years of follow-up. This duration shortened to 5.8 years in the presence of Intermittent SCD and 4.7 years in the presence of Persistent $S C D$. The differential risks across the 3 trajectories are further visible in the Kaplan-Meier curve in Fig. 2.

Three sensitivity analyses were conducted, with the results remaining robust even when some parts of the Cox regression were modified (Table 3). The first sensitivity analyses evaluated the utility of the SCD trajectories beyond one-time assessments of SCD, of which Intermittent SCD and Persistent SCD remained significant even after the additional adjustment of SCD at year 4. The second sensitivity analysis evaluated the alternative endpoint of dementia, with the results being similar to the primary findings (albeit with wider confidence intervals, due to the smaller number of participants who developed dementia during the follow-up period). In the third sensitivity analysis, the 3 identified trajectories were redefined using simplified rules to allow them to be easily applied in routine practice-No $S C D$ was redefined as participants who reported SCD in none of the 4 annual visits, Intermittent SCD as those who reported SCD in 1 to 2 of the annual visits, and Persistent SCD as those who reported SCD in 3 to 4 of the annual visits. Notably, the results remained consistent even when the trajectories were redefined using the simplified rules.

Participants were further split into 2 age strata based on median age of 75 years (i.e., $<75$ years and $\geq 75$ years), and the risks associated with the SCD trajectories were 
Table 1 Comparison of participant characteristics (at year 4) across the three trajectories of subjective cognitive decline $(n=5661)$

\begin{tabular}{|c|c|c|c|c|}
\hline Variable & No SCD $(n=3914)$ & Intermittent SCD $(n=1022)$ & Persistent SCD $(n=725)$ & $p$ value $^{\mathrm{a}}$ \\
\hline Age, median (IQR) & $74(69-80)$ & $75(70-82)$ & $75(69-81)$ & 0.002 \\
\hline Years of education, median (IQR) & $16(14-18)$ & $16(14-18)$ & $16(14-18)$ & 0.719 \\
\hline Male sex, $n(\%)$ & $1273(32.5)$ & $319(31.2)$ & $237(32.7)$ & 0.708 \\
\hline Ethnicity, n (\%) & & & & $<0.001$ \\
\hline White & $3248(83.0)$ & $786(76.9)$ & $576(79.5)$ & \\
\hline African American & $479(12.2)$ & $180(17.6)$ & $100(13.8)$ & \\
\hline Other/unknown & $187(4.8)$ & $56(5.5)$ & $49(6.8)$ & \\
\hline APOE e4 genotype, n (\%) & & & & 0.007 \\
\hline Two copies of e4 allele & $89(2.3)$ & $21(2.1)$ & $21(2.9)$ & \\
\hline One copy of e4 allele & $1012(25.9)$ & $249(24.4)$ & $198(27.3)$ & \\
\hline No e4 allele & $2615(66.8)$ & $678(66.3)$ & $449(61.9)$ & \\
\hline Unknown & $198(5.1)$ & $74(7.2)$ & $57(7.9)$ & \\
\hline Current smoker, $n(\%)$ & $187(4.8)$ & $33(3.2)$ & $38(5.2)$ & 0.068 \\
\hline Diabetes mellitus, $n(\%)$ & $480(12.3)$ & $145(14.2)$ & $105(14.5)$ & 0.103 \\
\hline Hypertension, $n$ (\%) & $2154(55.0)$ & $584(57.1)$ & $391(53.9)$ & 0.356 \\
\hline Hyperlipidemia, $n$ (\%) & $2211(56.5)$ & $609(59.6)$ & $425(58.6)$ & 0.153 \\
\hline MMSE score, median (IQR) & $30(29-30)$ & $29(28-30)$ & $29(28-30)$ & $<0.001$ \\
\hline GDS score, median (IQR) & $0(0-1)$ & $1(0-2)$ & $1(0-3)$ & $<0.001$ \\
\hline Presence of anxiety symptoms, $n(\%)$ & $209(5.3)$ & $100(9.8)$ & 79 (10.9) & $<0.001$ \\
\hline
\end{tabular}

IQR interquartile range, MMSE Mini-Mental State Examination, GDS Geriatric Depression Scale, SCD subjective cognitive decline

${ }^{a}$ Test of difference across the three trajectories of SCD: chi-square test for categorical variables, and Kruskal-Wallis test for continuous variables. Bold-faced $p$ values are $\leq 0.05$

separately examined in these 2 age strata. Results of the stratified analysis are presented in Table 4. Persistent $S C D$ was consistently significant across the age strata. In contrast, Intermittent SCD was only significant in the older age group ( $\geq 75$ years) and was no longer significant among younger participants ( $<75$ years). Notably, age also had compounding effects on the absolute risks of SCD trajectories, which is visible in the Kaplan-Meier curve in Fig. 3. Younger individuals ( $<75$ years) with $N o$ $S C D$ had less than $25 \%$ probability of developing MCI or dementia by the 10 years of follow-up. In contrast, older individuals ( $\geq 75$ years) with Persistent SCD had 25\% probability of developing MCI or dementia by 3.2 years
(95\% CI 2.2-4.3 years) and 75\% probability of developing MCI or dementia by 8.8 years ( $95 \%$ CI $8.2-9.5$ years).

\section{Discussion}

\section{Summary of findings}

This study utilized a large sample of cognitively normal individuals and a longitudinal study design, to investigate the association between SCD trajectories and risk of MCI and dementia. Using a data-driven approach, the study empirically identified 3 trajectories of SCD over 4 approximately annual visits, namely No $S C D$ (those who reported SCD in none of the 4 annual visits), Intermittent SCD (those who reported SCD in approximately 1

Table 2 Risk of mild cognitive impairment and dementia across the different trajectories of subjective cognitive decline $(n=5661)$

\begin{tabular}{|c|c|c|c|c|c|c|c|c|}
\hline \multirow[t]{2}{*}{ SCD trajectory } & \multirow{2}{*}{$\begin{array}{l}\text { No. of } \mathrm{MCl} \text { and } \\
\text { dementia / Total (\%) }\end{array}$} & \multicolumn{2}{|l|}{ Model $1^{b}$} & \multicolumn{2}{|l|}{ Model $2^{c}$} & \multicolumn{2}{|c|}{ Model 3 (final) $^{d}$} & \multirow{2}{*}{$\begin{array}{l}\text { Survival (25th } \\
\text { centile) in years } \\
(95 \% \mathrm{Cl})^{\mathrm{a}}\end{array}$} \\
\hline & & $\mathrm{HR}(95 \% \mathrm{Cl})$ & $p$ value & $\mathrm{HR}(95 \% \mathrm{Cl})$ & $p$ value & $\mathrm{HR}(95 \% \mathrm{Cl})$ & $p$ value & \\
\hline No SCD & $418 / 3914(10.7)$ & 1.0 (Ref) & Ref & 1.0 (Ref) & Ref & 1.0 (Ref) & Ref & $8.0(7.5-8.5)$ \\
\hline Intermittent SCD & $164 / 1022$ (16.0) & $1.5(1.3-1.8)$ & $<0.001$ & $1.5(1.2-1.8)$ & $<0.001$ & $1.4(1.1-1.7)$ & 0.001 & $5.8(5.3-6.4)$ \\
\hline Persistent SCD & $146 / 725(20.1)$ & $2.5(2.0-3.0)$ & $<0.001$ & $2.4(2.0-2.9)$ & $<0.001$ & $2.2(1.8-2.7)$ & $<0.001$ & $4.7(3.7-5.8)$ \\
\hline
\end{tabular}

SCD subjective cognitive decline, No number, $\mathrm{MCl}$ mild cognitive impairment, $\mathrm{Cl}$ confidence interval, $\mathrm{HR}$ hazard ratio, Ref reference group

${ }^{a}$ The time needed for a quarter of the participants to develop $\mathrm{MCl}$ or dementia. The $95 \% \mathrm{Cl}$ was computed with 1000 bootstrap sampling

${ }^{b}$ Cox regression included the SCD trajectories, as well as adjusted for covariates of age, sex, and ethnicity

'Covariate adjustment as in model 1, with additional adjustment for years of education, APOE e4 status, current smoking, diabetes mellitus, hypertension, hyperlipidemia, and Mini-Mental State Examination score

${ }^{\mathrm{d}}$ Covariate adjustment as in model 2, with additional adjustment for total score on Geriatric Depression Scale and presence of anxiety symptoms 


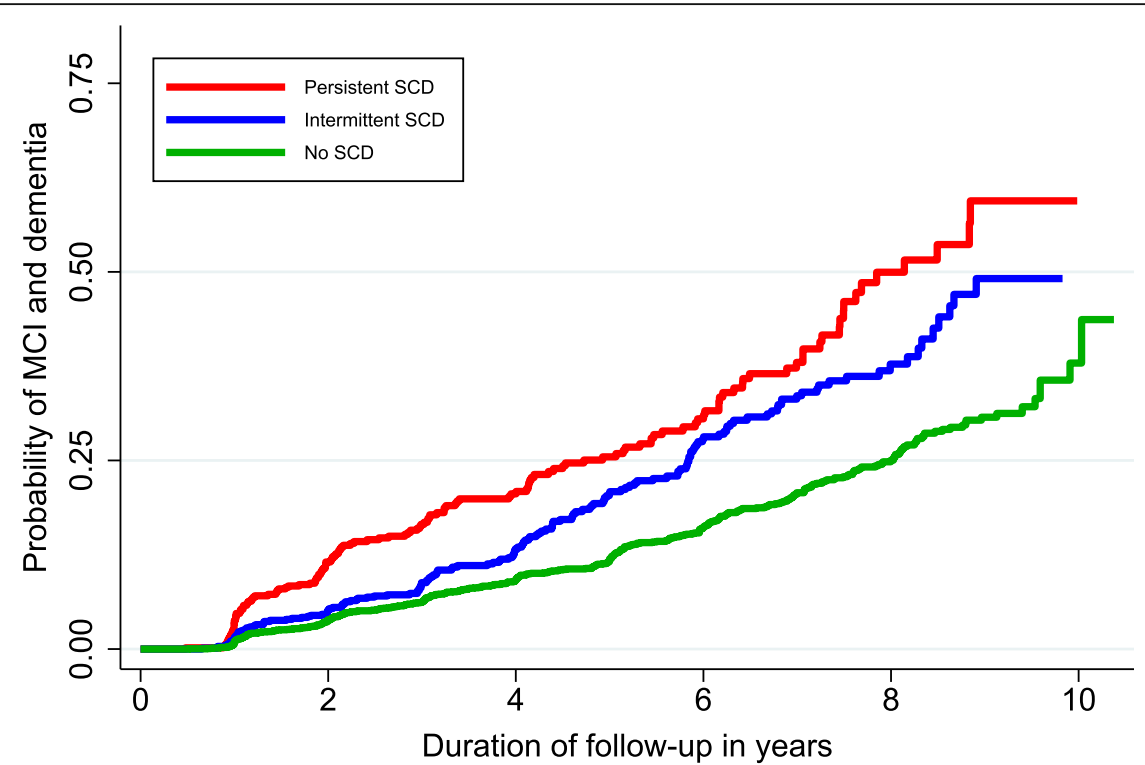

\begin{tabular}{|c|c|c|c|c|c|c|}
\hline $\begin{array}{l}\text { Number at risk } \\
\text { Persistent SCD }\end{array}$ & 728 & 498 & 272 & 153 & 39 & 0 \\
\hline Intermittent SCD & 1024 & 776 & 449 & 250 & 82 & 0 \\
\hline No SCD & 3910 & 2952 & 1852 & 1104 & 483 & \\
\hline
\end{tabular}

Fig. 2 Kaplan-Meier curves reflecting the risk of mild cognitive impairment (MCI) and dementia across the different trajectories of subjective cognitive decline (SCD) $(n=5661)$

to 2 annual visits), and Persistent SCD (those who reported SCD in approximately 3 to 4 annual visits). Compared to those without SCD, Intermittent SCD was associated with a higher risk of MCI and dementia, while Persistent SCD was associated with the highest risk. The findings remained significant even after adjusting for baseline SCD, which demonstrated the added utility of SCD trajectories in predicting $\mathrm{MCI}$ and dementia beyond one-time assessments of SCD. Further stratified analysis revealed that the risk related to Intermittent $S C D$ was primarily present in the older age group, while risk related to Persistent SCD was consistently present across the younger and older age groups. Notably, the stratified analysis also revealed the compounding effects of age-older individuals ( $\geq 75$ years) with Persistent SCD had $75 \%$ probability of developing MCI or dementia by 8.8 years of follow-up, in contrast to younger individuals $(<75$ years) with $N o$ $S C D$ who had less than $25 \%$ probability of developing MCI or dementia even by the end of the 10-year follow-up.

\section{Interpretation of findings}

The findings are consistent with recent literature on the relevance of longitudinal assessment of SCD in identifying individuals at high risk of neurocognitive disorders. In particular, the presence of Persistent $S C D$ over time has consistently been highlighted in recent literature as a key predictor of incident neurocognitive disorders [44-46]. This finding is understandable, given that neurocognitive disorders are conceptualized as progressive neurodegenerative diseases, and hence in the face of progressive neuropathological processes, individuals are more likely to

Table 3 Results from the three sensitivity analyses to evaluate the robustness of the main findings

\begin{tabular}{|c|c|c|c|c|c|c|}
\hline \multirow[t]{2}{*}{ SCD trajectory } & \multicolumn{2}{|c|}{$\begin{array}{l}\text { Additional adjustment for one-time } \\
\text { assessment of SCD at year } 4^{\text {a }}\end{array}$} & \multicolumn{2}{|c|}{$\begin{array}{l}\text { Primary endpoint of } \\
\text { dementia }^{\mathrm{a}}\end{array}$} & \multicolumn{2}{|c|}{$\begin{array}{l}\text { Redefining the trajectories } \\
\text { using simplified rules }{ }^{\mathrm{a}, \mathrm{b}}\end{array}$} \\
\hline & HR (95\% Cl) & $p$ value & HR $(95 \% \mathrm{Cl})$ & $p$ value & $\mathrm{HR}(95 \% \mathrm{Cl})$ & $p$ value \\
\hline No SCD & 1.0 (Ref) & Ref & 1.0 (Ref) & Ref & 1.0 (Ref) & Ref \\
\hline Intermittent SCD & $1.4(1.1-1.8)$ & 0.011 & $1.5(1.1-2.1)$ & 0.010 & $1.5(1.3-1.8)$ & $<0.001$ \\
\hline Persistent SCD & $2.1(1.6-2.8)$ & $<0.001$ & $2.2(1.5-3.2)$ & $<0.001$ & $2.6(2.0-3.4)$ & $<0.001$ \\
\hline
\end{tabular}

$S C D$ subjective cognitive decline, $H R$ hazard ratio, $C l$ confidence interval, Ref reference group

${ }^{a}$ Model adjusted for baseline variables of age, sex, ethnicity, years of education, APOE e4 status, current smoking, diabetes mellitus, hypertension, hyperlipidemia, Mini-Mental State Examination score, total score on Geriatric Depression Scale, and presence of anxiety symptoms

${ }^{\mathrm{b}}$ The following simplified rules were used to redefine the identified trajectories-No SCD was redefined as participants who reported SCD in none of the 4 annual visits, Intermittent SCD as those who reported SCD in 1 to 2 of the annual visits, and Persistent SCD as those who reported SCD in 3 to 4 of the annual visits 
Table 4 Risk of mild cognitive impairment and dementia across the different trajectories of subjective cognitive decline, further stratified by age $(n=5661)$

\begin{tabular}{|c|c|c|c|c|}
\hline SCD trajectory, stratified by age ${ }^{a}$ & $\begin{array}{l}\text { No. of } \mathrm{MCl} \text { and } \\
\text { dementia/total (\%) }\end{array}$ & $\begin{array}{l}\text { Hazard ratio } \\
(95 \% \mathrm{Cl})^{\mathrm{c}}\end{array}$ & $p$ value & $\begin{array}{l}\text { Survival (25th centile) in years } \\
(95 \% \mathrm{Cl})^{\mathrm{b}}\end{array}$ \\
\hline \multicolumn{5}{|l|}{ Participants $<75$ years } \\
\hline No SCD & $115 / 1980(5.8)$ & 1.0 (Ref) & Ref & Not available ${ }^{d}$ \\
\hline Intermittent SCD & $36 / 473(7.6)$ & $1.2(0.8-1.8)$ & 0.350 & $8.5(7.5-9.5)$ \\
\hline Persistent SCD & 43/362 (11.9) & $1.9(1.2-2.9)$ & 0.003 & $6.9(5.8-8.0)$ \\
\hline \multicolumn{5}{|l|}{ Participants $\geq 75$ years } \\
\hline No SCD & $303 / 1934$ (15.7) & 1.0 (Ref) & Ref & $6.2(5.7-6.6)$ \\
\hline Intermittent SCD & $128 / 549(23.3)$ & $1.4(1.2-1.8)$ & 0.001 & $4.4(3.8-5.0)$ \\
\hline Persistent SCD & $103 / 363(28.4)$ & $2.2(1.8-2.8)$ & $<0.001$ & $3.2(2.2-4.3)$ \\
\hline
\end{tabular}

$S C D$ subjective cognitive decline, $M C l$ mild cognitive impairment, $C l$ confidence interval, Ref reference group

${ }^{\text {aP }}$ articipants were stratified into 2 equal-sized age groups based on median age of 75 years

${ }^{\mathrm{b}}$ The time needed for a quarter of the participants to develop $\mathrm{MCl}$ or dementia. The $95 \% \mathrm{Cl}$ was computed with 1000 bootstrap sampling

'Model adjusted for baseline variables of age, sex, ethnicity, years of education, APOE e4 status, current smoking, diabetes mellitus, hypertension, hyperlipidemia,

Mini-Mental State Examination score, total score on Geriatric Depression Scale, and presence of anxiety symptoms

${ }^{\mathrm{d} N o t}$ available, because less than one-quarter of participants in this group developed $\mathrm{MCl}$ or dementia by the end of the follow-up period

experience persistent rather than transient symptoms of SCD [43, 44]. In contrast, the evidence on the relevance of Intermittent $S C D$ was more conflicting in the literature, with one study showing no association with incident neurocognitive disorders [44], another study showing significant association only with informant-reports and not selfreports of SCD [45], while yet another study showing significant association but in the negative direction (i.e., presence of Intermittent SCD was associated with a lower risk of neurocognitive disorders) [46].
There may be a plausible explanation on the association between Transient SCD and incident neurocognitive disorders. As shown in this study, Transient SCD can still be relevant, but primarily in the older population and not among the younger individuals. It is possible that in the younger population and in lower-risk individuals (such as in community samples) [47, 48], the association between Transient SCD and neurocognitive disorders may be diluted by many other nonneurodegenerative causes such as psychiatric conditions,
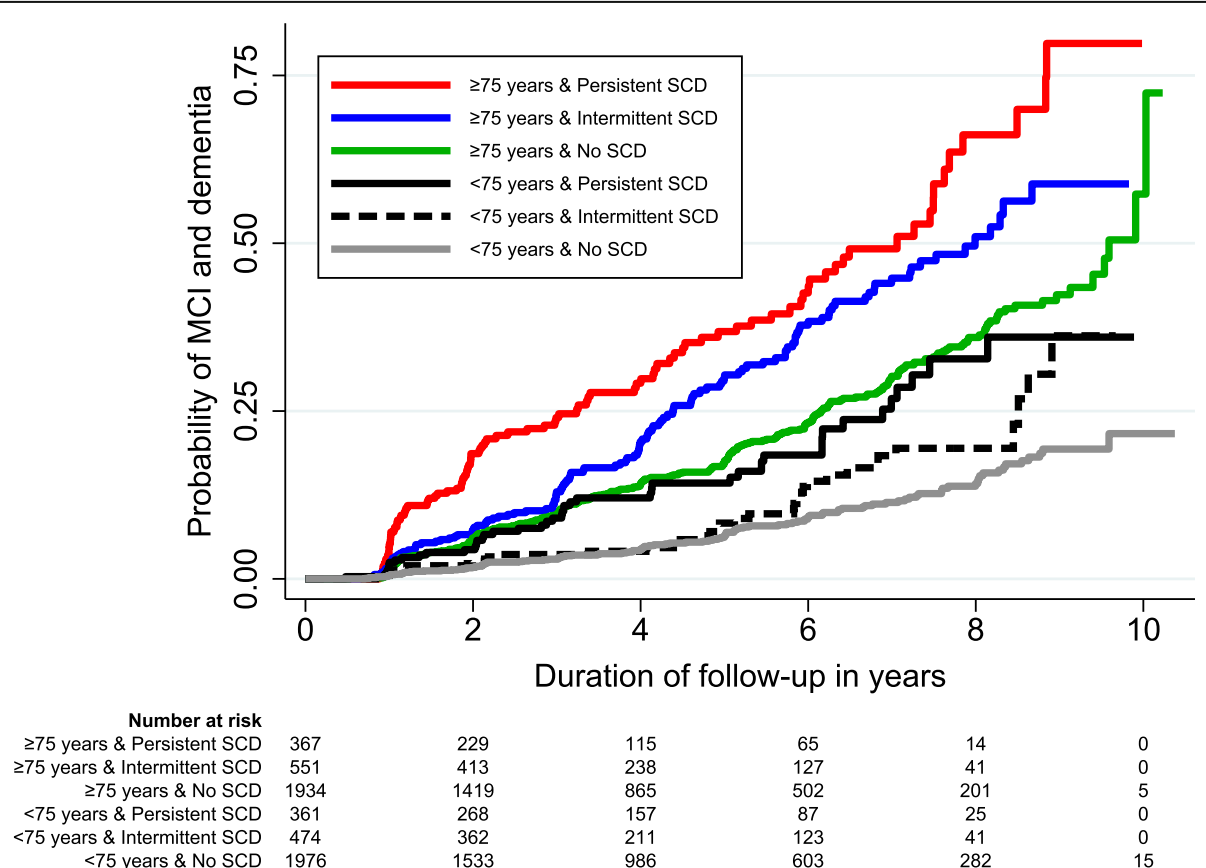

$\begin{array}{cc}229 & 115 \\ 413 & 238 \\ 1419 & 865 \\ 268 & 157 \\ 362 & 211 \\ 1533 & 986\end{array}$

65
127
502
87
123
603

$\begin{array}{cc}14 & 0 \\ 41 & 0 \\ 201 & 5 \\ 25 & 0 \\ 41 & 0 \\ 282 & 15\end{array}$

Fig. 3 Kaplan-Meier curves reflecting the risk of mild cognitive impairment (MCl) and dementia, stratified by different age groups and trajectories of subjective cognitive decline (SCD) $(n=5661)$ 
personality traits, negative self-beliefs, excessive selfattention, and distressing life events [43-46, 49]. Possibly, the association between Transient SCD and neurocognitive disorders may only become more apparent when these other non-neurodegenerative causes can be clearly filtered out, such as in the previous study [45], when the Transient SCD is reported by informant rather than self (and hence we may possibly filter out pure psychiatric or emotional causes that can influence an individual's subjective reporting of cognitive decline), or such as in the current study, when most of the participants voluntarily visited the ADC to participate in longitudinal studies on cognition (which may have filtered out those without any concerns about cognition) [4749] and when the Transient SCD is reported in older rather than younger age (which may have identified those with higher likelihood of neurodegenerative rather than non-neurodegenerative causes of SCD) [1, 49].

The differential risks related to Intermittent and Persistent $S C D$, especially in the older age group, may have a plausible explanation relating to the underlying neurobiological processes. The manifestations of Transient and Persistent $S C D$ may possibly involve an interplay between neuropathological load [50-53] and compensatory hyperactivation of the brain [54], whereby Transient $S C D$ may reflect very early neuropathological processes which are stabilized by compensatory hyperactivation of the brain [54], while Persistent SCD may be explained by the rising neuropathological load which overwhelms the initial compensatory response [54]. This hypothesis has some support from the early evidence in extant literature. In prior studies involving individuals with SCD, higher amyloid load in the brain has been associated with greater severity of SCD [50-52], as well as a higher likelihood of reporting SCD over time [53]. At the same time, prior functional magnetic resonance imaging studies in SCD have demonstrated decreased activation in the hippocampus, which resulted in compensatory hyperactivation in the prefrontal cortex to maintain normal cognitive performance as well as subsequent decreased activation in the prefrontal cortex that marked the onset of subtle cognitive deficits [54]. The presence of such brain compensation may possibly have maintained the cognitive performance even in the presence of neurodegenerative processes, and hence the experience of SCD may not appear to be persistent initially. However, with rising load of neuropathology, the initial brain compensation may no longer be efficient in maintaining the cognitive performance [54], which may then mark the persistent and consistent experience of SCD over time. While the above explanation may seem plausible, readers should be cautioned that this remains a hypothesis that requires further validation in future studies, and if shown to be true, it may potentially enrich our understanding on the temporal dynamics between SCD and neurocognitive disorders.

\section{Implication of findings}

The findings may potentially have implications to the present SCD criteria that have been operationalized since 2014 [1]. The extant literature has demonstrated the usefulness of SCD-based on one-time assessments-in predicting $\mathrm{MCI}$ and dementia [1, 7-9]. In addition to the available evidence, the current study further substantiates the usefulness of SCD-based on longitudinal assessment-in providing even more granular information on the risk of MCI and dementia. This can be especially pertinent given that SCD may manifest up to 15 years before incident $\mathrm{MCI}$ [8], and the longitudinal measurement of SCD during this latent period may allow us to further classify individuals into three levels of risk: low risk (absence of SCD in all annual visits), high risk (intermittent reporting of SCD during annual visits, especially among older individuals), and very high risk (persistent reporting of SCD during annual visits). Notably, these three risk strata are also not inconsistent with the current SCD framework that classifies individuals into three categories: no SCD, SCD, and SCD plus (which includes those with specific features of SCD that further increase the likelihood of neurocognitive disorders, such as subjective decline in memory rather than other domains of cognition, onset of SCD at an older age, and worries about SCD) $[1,8,49]$. In this sense, individuals with Intermittent SCD would have fulfilled the basic definition of SCD, while those with Persistent SCD demonstrated an even higher risk of neurocognitive disorders and would have fallen under the category of SCD plus. In other words, in the light of the current findings, future revisions of the SCD criteria may consider formally incorporating "the presence of persistent SCD over several years" as one of the key criteria within SCD plus, which is also consistent with a similar proposition that was made by a recent review on SCD [49].

The findings may also have implications to the operationalization of SCD measures in routine practice. It is noteworthy that SCD measure in this study was merely based on a single question with binary responses (yes/ no), and only focused on the memory domain. Arguably, for the longitudinal tracking of SCD, such single-item question may not be as sensitive as multi-item questionnaires which are based on continuous rating scales and cover both memory and non-memory domains $[8,55]$. Yet, as shown in this study, this brief measure can still be sufficiently useful to capture clinically meaningful trajectories of SCD. It provides a convenient approach to operationalize the routine screening of SCD among cognitively normal individuals and can be especially relevant to large-scale epidemiological studies which often prefer 
brief screening tools over their longer variants (due to the need to accommodate a large number of measurement scales within the observational studies). Notwithstanding the above, further research can still be helpful to examine whether the use of multi-item questionnaires may be more effective in capturing the longitudinal changes of SCD.

The findings may potentially also have implications to patients who present with SCD in routine clinical practice. To date, the utility of diagnosing SCD in routine clinical care remains contentious $[43,56]$, due to the association of SCD with non-neurodegenerative causes and its lack of specificity in predicting neurocognitive disorders $[49,56]$. Indeed, such limitation of SCD is also evident in the findings of this study, whereby participants in the highest risk stratum of SCD trajectory (i.e., Persistent SCD) only had around 50\% probability of progressing to neurocognitive disorders by the end of the 10-year follow-up (Fig. 2). However, the predictive utility of SCD may potentially be improved when SCD trajectories are used in combination with the other SCD plus features. Such argument has had some precedence in the literature, whereby Persistent SCD-when co-occurring with worries about SCD [44] or reported by informant [45] (both of which are features of SCD plus)-were shown to further increase the risk of neurocognitive disorders. In the case of the current study, when the SCD trajectories were used in combination with age group (which conceptually, is also a feature of SCD plus), those in the highest risk stratum (i.e., $\geq 75$ years and Persistent $S C D$ ) had more than $75 \%$ probability of developing neurocognitive disorders by 10 years (Fig. 3). This is in contrast to the less than $25 \%$ probability by 10 years among those in the lowest risk stratum $(<75$ years and No $S C D$ ). Such improvement in the specificity of predicting neurocognitive disorders may potentially have implications to the management of patients with SCD in clinical practice [43]. It may allow us to employ more personalized approaches across different levels of risk, whereby those at higher risk of neurocognitive disorders may be identified for more intensive interventions (e.g., risk factor modification, physical exercise, and cognitive training) $[49,57,58]$, enrollment into preventive trials $[3,43]$, as well as closer monitoring of cognitive function over time to allow timely diagnosis of cognitive impairment [59-62].

\section{Limitations}

Several limitations should be considered. First, the participants in the study involved those who volunteered at the ADC. They may be more representative of patients who voluntarily present to healthcare settings than those in the community. Second, to examine the SCD trajectories in the first 4 years of follow-up, the study had to exclude 828 individuals who developed MCI or dementia from year 2 to year 4 (Additional file 2). These 828 excluded individuals were much different from the included participants (they had older age, higher proportion of APOE e4 allele, higher GDS scores, and higher proportion of anxiety symptoms as shown in Additional file 6) and likely represent a separate group which is at much higher risk of neurocognitive disorders. Keeping in mind of this limitation, the study findings are more applicable to individuals who generally have a lower baseline risk of neurocognitive disorders, among whom the SCD trajectories remain useful to provide further risk stratification. Third, the SCD measure in this study was based on a single-question and focused on the memory domain. Such SCD measure may not have captured the full range of memory concerns or other nonmemory domains $[55,63]$. Fourth, to adjust for the potential confounding effects of anxiety symptoms, a single yes/no question was used to capture the presence of anxiety symptoms in this study. Such single question may not be as sensitive as multi-item questionnaires in identifying the presence of anxiety symptoms. Fifth, inasmuch as this study adjusted for many covariates in the statistical models (such as depressive and anxiety symptoms), there are still other potential confounders (such as personality traits and distressing life events) [44-46, 49] that were not captured in the National Alzheimer's Coordinating Center database and hence could not be adjusted for in this study. Sixth, the diagnoses of MCI and dementia were made by single clinicians in $30.3 \%$ of the participants. They may not necessarily be as accurate as those made via consensus conference. Seventh, the primary analysis from the Cox regression was fitted on the basis of assigned trajectories and did not take into account the uncertainty in group membership of each individual, which might mean that the variance estimates are underestimated. However, it is unlikely that this would affect the general conclusions, given that the Average Posterior Probabilities for the trajectories were high (ranging between 0.78 to 0.81 ) and the results remained consistent even when the trajectories were redefined using alternate, simplified rules (in the fourth sensitivity analysis).

\section{Conclusion}

This study identified 3 trajectories of SCD over time, namely No SCD in all 4 annual visits, Intermittent $S C D$ in 1 to 2 of the annual visits, and Persistent SCD in 3 to 4 of the annual visits. Intermittent SCD predicted a higher risk of neurocognitive disorders but only in the older age group, while Persistent SCD predicted the highest risk consistently across the younger and older age groups. Age compounded the effects of the trajectories, whereby older individuals with Persistent SCD had > 
$75 \%$ probability of developing neurocognitive disorders by 10 years, in contrast to $<25 \%$ probability by 10 years in younger individuals with No SCD. The findings demonstrate the utility of SCD trajectories-especially when used in combination with age strata-in identifying high-risk populations for preventive interventions and trials. They also suggest a potential modification to the current research criteria of SCD, with the inclusion of "persistent SCD over several years" as one of the key features within SCD plus.

\section{Supplementary information}

Supplementary information accompanies this paper at https://doi.org/10. 1186/s13195-020-00699-y.

Additional file 1. Details on the conduct of inverse probability weighting to account for those who did not have follow-up data beyond Year 4.

Additional file 2. Participant enrolment and exclusion details.

Additional file 3 Demographic information of the study participants at Year $4(n=5661)$, and comparison between those with and without longitudinal follow-up data beyond Year 4.

Additional file 4. Model fit indices in latent class growth curve analysis. The model that fulfilled the criteria of adequate fit is highlighted in bold.

Additional file 5. Trajectories of subjective cognitive decline (SCD) during the first 4 years of the study, with each grey line in the figure representing the trajectory for individual participant over Year 1 to Year 4.

Additional file 6. Comparison of demographic information at Year 1, between the participants of this study and those that were excluded because they developed mild cognitive impairment or dementia between Year 2 and Year 4.

\section{Abbreviations \\ ADC: Alzheimer's Disease Centers; BIC: Bayesian Information Criterion; Cl: Confidence interval; GDS: Geriatric Depression Scale; HR: Hazard ratio; IQR: Inter-quartile range; IPW: Inverse probability weighting; MCI: Mild cognitive impairment; MMSE: Mini-Mental State Examination; NIA- AA: National Institute on Aging-Alzheimer's Association; Ref: Reference group; SCD: Subjective cognitive decline}

\section{Acknowledgements}

The National Alzheimer's Coordinating Center (NACC) database is funded by NIA/NIH Grant U01 AG016976. NACC data are contributed by the NIA-funded ADC: P30 AG019610 (PI Eric Reiman, MD), P30 AG013846 (PI Neil Kowall, MD), P50 AG008702 (PI Scott Small, MD), P50 AG025688 (PI Allan Levey, MD, PhD), P50 AG047266 (PI Todd Golde, MD, PhD), P30 AG010133 (PI Andrew Saykin, PsyD), P50 AG005146 (PI Marilyn Albert, PhD), P50 AG005134 (PI Bradley Hyman, MD, PhD), P50 AG016574 (PI Ronald Petersen, MD, PhD), P50 AG005138 (PI Mary Sano, PhD), P30 AG008051 (PI Thomas Wisniewski, MD), P30 AG013854 (PI M. Marsel Mesulam, MD), P30 AG008017 (PI Jeffrey Kaye, MD), P30 AG010161 (PI David Bennett, MD), P50 AG047366 (PI Victor Henderson, MD, MS), P30 AG010129 (PI Charles DeCarli, MD), P50 AG016573 (PI Frank LaFerla, PhD), P50 AG005131 (PI James Brewer, MD, PhD), P50 AG023501 (PI Bruce Miller, MD), P30 AG035982 (PI Russell Swerdlow, MD), P30 AG028383 (PI Linda Van Eldik, PhD), P30 AG053760 (PI Henry Paulson, MD, PhD), P30 AG010124 (PI John Trojanowski, MD, PhD), P50 AG005133 (PI Oscar Lopez, MD), P50 AG005142 (PI Helena Chui, MD), P30 AG012300 (PI Roger Rosenberg, MD), P30 AG049638 (PI Suzanne Craft, PhD), P50 AG005136 (PI Thomas Grabowski, MD), P50 AG033514 (PI Sanjay Asthana, MD, FRCP), P50 AG005681 (PI John Morris, MD), P50 AG047270 (PI Stephen Strittmatter, $\mathrm{MD}, \mathrm{PhD})$.

\section{Author's contributions}

The author read and approved the final manuscript.

\section{Funding}

TML was supported by research grants under the National Medical Research Council of Singapore (grant number NMRC/Fellowship/0030/2016 and NMRC/CSSSP/0014/2017). The funding sources had no involvement in any part of the project.

\section{Availability of data and materials}

The data were obtained from the National Alzheimer's Coordinating Center (NACC). For further information on access to the database, please contact NACC (contact details can be found at https://www.alz.washington.edu/WEB/ researcher_home.html).

Ethics approval and consent to participate

All contributing Alzheimer's Disease Centers obtained informed consent from their participants, as well as received approval by their local institutional review boards. Research using the NACC database was also approved by the University of Washington Institutional Review Board.

\section{Consent for publication}

Not applicable.

\section{Competing interests}

The author declares no competing interests.

Received: 1 December 2019 Accepted: 1 October 2020

Published online: 27 October 2020

\section{References}

1. Jessen F, Amariglio RE, van Boxtel M, Breteler M, Ceccaldi M, Chetelat $G$, Dubois B, Dufouil C, Ellis KA, van der Flier WM, et al. A conceptual framework for research on subjective cognitive decline in preclinical Alzheimer's disease. Alzheimers Dement. 2014;10(6):844-52.

2. Hill NL, Mogle J, Wion R, Munoz E, DePasquale N, Yevchak AM, Parisi JM. Subjective cognitive impairment and affective symptoms: a systematic review. Gerontologist. 2016;56(6):e109-27.

3. Liew TM. Depression, subjective cognitive decline, and the risk of neurocognitive disorders. Alzheimers Res Ther. 2019;11(1):70.

4. Mitchell AJ. Is it time to separate subjective cognitive complaints from the diagnosis of mild cognitive impairment? Age Ageing. 2008;37(5):497-9.

5. Singh-Manoux A, Dugravot A, Ankri J, Nabi H, Berr C, Goldberg M, Zins M, Kivimaki M, Elbaz A. Subjective cognitive complaints and mortality: does the type of complaint matter? J Psychiatr Res. 2014;48(1):73-8.

6. Holmen J, Langballe E, Midthjell K, Lingaas Holmen T, Fiksaune A, Saltvedt I, Tambs K. Gender differences in subjective memory impairment in a general population: the HUNT study, Norway, vol. 1; 2013.

7. Mitchell AJ, Beaumont H, Ferguson D, Yadegarfar M, Stubbs B. Risk of dementia and mild cognitive impairment in older people with subjective memory complaints: meta-analysis. Acta Psychiatr Scand. 2014;130(6):43951.

8. Molinuevo JL, Rabin LA, Amariglio R, Buckley R, Dubois B, Ellis KA, Ewers M, Hampel H, Kloppel S, Rami L, et al. Implementation of subjective cognitive decline criteria in research studies. Alzheimers Dement. 2017;13(3):296-311.

9. Jack CR Jr, Bennett DA, Blennow K, Carrillo MC, Dunn B, Haeberlein SB, Holtzman DM, Jagust W, Jessen F, Karlawish J, et al. NIA-AA Research Framework: toward a biological definition of Alzheimer's disease. Alzheimers Dement. 2018;14(4):535-62.

10. McKhann GM, Knopman DS, Chertkow H, Hyman BT, Jack CR, Kawas CH, Klunk WE, Koroshetz WJ, Manly JJ, Mayeux R, et al. The diagnosis of dementia due to Alzheimer's disease: recommendations from the National Institute on Aging-Alzheimer's Association workgroups on diagnostic guidelines for Alzheimer's disease. Alzheimer's Dement. 2011;7(3):263-9.

11. Beekly DL, Ramos EM, van Belle G, Deitrich W, Clark AD, Jacka ME, Kukull WA. The National Alzheimer's Coordinating Center (NACC) Database: an Alzheimer disease database. Alzheimer Dis Assoc Disord. 2004;18(4):270-7.

12. Folstein MF, Folstein SE, McHugh PR. "Mini-mental state". A practical method for grading the cognitive state of patients for the clinician. J Psychiatr Res. 1975;12(3):189-98.

13. Sheikh JI, Yesavage JA. Geriatric Depression Scale (GDS): recent evidence and development of a shorter version. Clin Gerontol. 1986;5(1-2):165-73.

14. Petersen RC, Morris JC. Mild cognitive impairment as a clinical entity and treatment target. Arch Neurol. 2005;62(7):1160-3 discussion 1167. 
15. McKhann G, Drachman D, Folstein M, Katzman R, Price D, Stadlan EM: Clinical diagnosis of Alzheimer's disease. Report of the NINCDS-ADRDA Work Group* under the auspices of Department of Health and Human Services Task Force on Alzheimer's Disease 1984, 34(7):939-939.

16. American Psychiatric Association. Diagnostic and Statistical Manual of Mental Disorders: DSM-IV-TR. Washington: American Psychiatric Association; 2000.

17. Román GC, Tatemichi TK, Erkinjuntti T, Cummings JL, Masdeu JC, Garcia JH, Amaducci L, Orgogozo J-M, Brun A, Hofman A, et al. Vascular dementia. Diagn Criteria Res Stud. 1993;43(2):250.

18. Rascovsky K, Hodges JR, Knopman D, Mendez MF, Kramer JH, Neuhaus J, van Swieten JC, Seelaar H, Dopper EGP, Onyike CU, et al. Sensitivity of revised diagnostic criteria for the behavioural variant of frontotemporal dementia. Brain. 2011;134(Pt 9):2456-77.

19. Bensimon $G$, Ludolph A, Agid $Y$, Vidailhet M, Payan C, Leigh PN. Riluzole treatment, survival and diagnostic criteria in Parkinson plus disorders: the NNIPPS study. Brain. 2009;132(Pt 1):156-71.

20. Armstrong MJ, Litvan I, Lang AE, Bak TH, Bhatia KP, Borroni B, Boxer AL, Dickson DW, Grossman M, Hallett M, et al. Criteria for the diagnosis of corticobasal degeneration. Neurology. 2013;80(5):496-503.

21. Brooks BR, Miller RG, Swash M, Munsat TL. El Escorial revisited: revised criteria for the diagnosis of amyotrophic lateral sclerosis. Amyotroph Lateral Scler Other Motor Neuron Disord. 2000;1(5):293-9.

22. Neary D, Snowden JS, Gustafson L, Passant U, Stuss D, Black S, Freedman M, Kertesz A, Robert PH, Albert M, et al. Frontotemporal lobar degeneration: a consensus on clinical diagnostic criteria. Neurology. 1998;51(6):1546-54.

23. Litvan I, Agid Y, Calne D, Campbell G, Dubois B, Duvoisin RC, Goetz CG, Golbe LI, Grafman J, Growdon JH, et al. Clinical research criteria for the diagnosis of progressive supranuclear palsy (Steele-Richardson-Olszewski syndrome): report of the NINDS-SPSP international workshop. Neurology. 1996;47(1):1-9.

24. Litvan I, Bhatia KP, Burn DJ, Goetz CG, Lang AE, McKeith I, Quinn N, Seth KD, Shults C, Wenning GK. Movement Disorders Society Scientific Issues Committee report: SIC Task Force appraisal of clinical diagnostic criteria for Parkinsonian disorders. Mov Disord. 2003;18(5):467-86.

25. McKeith IG, Boeve BF, Dickson DW, Halliday G, Taylor JP, Weintraub D, Aarsland D, Galvin J, Attems J, Ballard CG, et al. Diagnosis and management of dementia with Lewy bodies: fourth consensus report of the DLB Consortium. Neurology. 2017;89(1):88-100

26. McKeith IG, Dickson DW, Lowe J, Emre M, O'Brien JT, Feldman H, Cummings J, Duda JE, Lippa C, Perry EK, et al. Diagnosis and management of dementia with Lewy bodies: third report of the DLB consortium. Neurology. 2005; 65(12):1863-72.

27. Jones BL, Nagin DS. A note on a Stata plugin for estimating group-based trajectory models. Sociol Methods Res. 2013;42(4):608-13.

28. Nagin DS. Group-Based Modeling of Development. Massachusetts: Harvard University Press; 2005.

29. Baumgart M, Snyder HM, Carrillo MC, Fazio S, Kim H, Johns H. Summary of the evidence on modifiable risk factors for cognitive decline and dementia: a population-based perspective. Alzheimers Dement. 2015;11(6):718-26.

30. Rothman KJ. Modern epidemiology, 3rd ed. edn. Philadelphia: Wolters Kluwer Health/Lippincott Williams \& Wilkins; 2008.

31. Burmester B, Leathem J, Merrick P. Subjective cognitive complaints and objective cognitive function in aging: a systematic review and meta-analysis of recent cross-sectional findings. Neuropsychol Rev. 2016;26(4):376-93.

32. Reid LM, Maclullich AM. Subjective memory complaints and cognitive impairment in older people. Dement Geriatr Cogn Disord. 2006;22(5-6): 471-85.

33. Liew TM. Neuropsychiatric symptoms in cognitively normal older persons, and the association with Alzheimer's and non-Alzheimer's dementia. Alzheimers Res Ther. 2020;12(1):35.

34. Liew TM. Symptom clusters of neuropsychiatric symptoms in mild cognitive impairment and their comparative risks of dementia: a cohort study of 8530 older persons. J Am Med Dir Assoc. 2019;20(8):1054.e1051-9.

35. Liew TM, Yu J, Mahendran R, Ng TP, Kua EH, Feng L. Neuropsychiatric and cognitive subtypes among community-dwelling older persons and the association with DSM-5 mild neurocognitive disorder: latent class analysis. J Alzheimers Dis. 2018;62(2):675-86.

36. Santabarbara J, Lipnicki DM, Villagrasa B, Lobo E, Lopez-Anton R. Anxiety and risk of dementia: systematic review and meta-analysis of prospective cohort studies. Maturitas. 2019;119:14-20.
37. Gulpers B, Ramakers I, Hamel R, Kohler S, Oude Voshaar R, Verhey F. Anxiety as a predictor for cognitive decline and dementia: a systematic review and meta-analysis. Am J Geriatr Psychiatry. 2016;24(10):823-42.

38. Becker E, Orellana Rios CL, Lahmann C, Rucker G, Bauer J, Boeker M. Anxiety as a risk factor of Alzheimer's disease and vascular dementia. Br J Psychiatry. 2018;213(5):654-60.

39. Liew TM. Subjective cognitive decline, anxiety symptoms, and the risk of mild cognitive impairment and dementia. Alzheimers Res Ther. 2020;12(1): 107.

40. StataCorp. Stata survival analysis reference manual release 14. Texas: Stata Press; 2015.

41. Seaman SR, White IR. Review of inverse probability weighting for dealing with missing data. Stat Methods Med Res. 2013;22(3):278-95.

42. Morley JE, Morris JC, Berg-Weger M, Borson S, Carpenter BD, Del Campo N, Dubois B, Fargo K, Fitten LJ, Flaherty JH, et al. Brain health: the importance of recognizing cognitive impairment: an IAGG consensus conference. J Am Med Dir Assoc. 2015;16(9):731-9.

43. McWhirter L, Ritchie C, Stone J, Carson A. Functional cognitive disorders: a systematic review. Lancet Psychiatry. 2020;7(2):191-207.

44. Wolfsgruber S, Kleineidam L, Wagner M, Mösch E, Bickel H, Lühmann D, Ernst A, Wiese B, Steinmann S, König HH, et al. Differential risk of incident Alzheimer's disease dementia in stable versus unstable patterns of subjective cognitive decline. J Alzheimers Dis. 2016;54(3):1135-46.

45. van Harten AC, Mielke MM, Swenson-Dravis DM, Hagen CE, Edwards KK, Roberts RO, Geda YE, Knopman DS, Petersen RC. Subjective cognitive decline and risk of MCl: the Mayo Clinic Study of Aging. Neurology. 2018; 91(4):e300-12.

46. Roehr S, Villringer A, Angermeyer MC, Luck T, Riedel-Heller SG. Outcomes of stable and unstable patterns of subjective cognitive decline - results from the Leipzig Longitudinal Study of the Aged (LEILA75+). BMC Geriatr. 2016; 16(1):180.

47. Slot RER, Sikkes SAM, Berkhof J, Brodaty H, Buckley R, Cavedo E, Dardiotis E, Guillo-Benarous F, Hampel H, Kochan NA, et al. Subjective cognitive decline and rates of incident Alzheimer's disease and non-Alzheimer's disease dementia. Alzheimers Dement. 2019;15(3):465-76.

48. Snitz BE, Wang T, Cloonan YK, Jacobsen E, Chang CH, Hughes TF, Kamboh MI, Ganguli M. Risk of progression from subjective cognitive decline to mild cognitive impairment: the role of study setting. Alzheimers Dement. 2018; 14(6):734-42.

49. Jessen F, Amariglio RE, Buckley RF, van der Flier WM, Han Y, Molinuevo JL, Rabin L, Rentz DM, Rodriguez-Gomez O, Saykin AJ, et al. The characterisation of subjective cognitive decline. Lancet Neurol. 2020;19(3): 271-8.

50. Amariglio RE, Becker JA, Carmasin J, Wadsworth LP, Lorius N, Sullivan C, Maye JE, Gidicsin C, Pepin LC, Sperling RA, et al. Subjective cognitive complaints and amyloid burden in cognitively normal older individuals. Neuropsychologia. 2012;50(12):2880-6.

51. Perrotin A, Mormino EC, Madison CM, Hayenga AO, Jagust WJ. Subjective cognition and amyloid deposition imaging: a Pittsburgh Compound B positron emission tomography study in normal elderly individuals. Arch Neurol. 2012;69(2):223-9.

52. Snitz BE, Weissfeld LA, Cohen AD, Lopez OL, Nebes RD, Aizenstein HJ, McDade E, Price JC, Mathis CA, Klunk WE. Subjective cognitive complaints, personality and brain amyloid-beta in cognitively normal older adults. Am J Geriatr Psychiatry. 2015;23(9):985-93.

53. Amariglio RE, Buckley RF, Mormino EC, Marshall GA, Johnson KA, Rentz DM, Sperling RA. Amyloid-associated increases in longitudinal report of subjective cognitive complaints. Alzheimers Dement (N Y). 2018;4:444-9.

54. Mizuno A, Ly M, Aizenstein HJ. A Homeostatic Model of Subjective Cognitive Decline. Brain Sci. 2018;8(12):228.

55. Liew TM, Yap P, Ng TP, Mahendran R, Kua EH, Feng L. Symptom clusters of subjective cognitive decline amongst cognitively normal older persons and their utilities in predicting objective cognitive performance: structural equation modelling. Eur J Neurol. 2019;26(9):1153-60.

56. Howard R. Subjective cognitive decline: what is it good for? Lancet Neurol. 2020;19(3):203-4.

57. Livingston G, Sommerlad A, Orgeta V, Costafreda SG, Huntley J, Ames D, Ballard C, Banerjee S, Burns A, Cohen-Mansfield J, et al. Dementia prevention, intervention, and care. Lancet. 2017;390(10113):2673-734.

58. Ngandu T, Lehtisalo J, Solomon A, Levalahti E, Ahtiluoto S, Antikainen R, Backman L, Hanninen T, Jula A, Laatikainen T, et al. A 2 year multidomain 
intervention of diet, exercise, cognitive training, and vascular risk monitoring versus control to prevent cognitive decline in at-risk elderly people (FINGER): a randomised controlled trial. Lancet. 2015;385(9984):2255-63.

59. Liew TM. Developing a brief neuropsychological battery for early diagnosis of cognitive impairment. J Am Med Dir Assoc. 2019;20(8):1054.e1011-20

60. Liew TM. Active case finding of dementia in ambulatory care settings: a comparison of three strategies. Eur J Neurol. 2020. https://doi.org/10.1111/ ene.14353. Epub ahead of print.

61. Liew TM. A 4-Item Case-Finding Tool to Detect Dementia in Older Persons. J Am Med Dir Assoc. 2019;20(12):1529-34.e1526.

62. Liew TM. The Optimal Short Version of Montreal Cognitive Assessment in Diagnosing Mild Cognitive Impairment and Dementia. J Am Med Dir Assoc. 2019;20(8):1055 e1051-1055 e1058.

63. Rabin LA, Smart CM, Crane PK, Amariglio RE, Berman LM, Boada M, Buckley RF, Chetelat G, Dubois B, Ellis KA, et al. Subjective cognitive decline in older adults: an overview of self-report measures used across 19 international research studies. J Alzheimers Dis. 2015;48(Suppl 1):S63-86.

\section{Publisher's Note}

Springer Nature remains neutral with regard to jurisdictional claims in published maps and institutional affiliations.

Ready to submit your research? Choose BMC and benefit from:

- fast, convenient online submission

- thorough peer review by experienced researchers in your field

- rapid publication on acceptance

- support for research data, including large and complex data types

- gold Open Access which fosters wider collaboration and increased citations

- maximum visibility for your research: over $100 \mathrm{M}$ website views per year

At BMC, research is always in progress.

Learn more biomedcentral.com/submissions 